\title{
A critical analysis of the degree of conversion of resin-based luting cements
}

\author{
Jaime Dutra NORONHA FILHO'1, Natasha Lamego BRANDÃO1, Laiza Tatiana POSKUS², \\ José Guilherme Antunes GUIMARÃES ${ }^{2}$, Eduardo Moreira da SILVA² \\ 1- DDS, Undergraduate student, Department of Restorative Dentistry, School of Dentistry, Federal Fluminense University, Niterói, RJ, Brazil. \\ 2- DDS, MSc, PhD, Associate Professor Department of Restorative Dentistry, School of Dentistry, Federal Fluminense University, Niterói, RJ, Brazil.
}

Corresponding address: Dr. Eduardo Moreira da Silva - Universidade Federal Fluminense / Faculdade de Odontologia - Rua Mário Santos Braga, $\mathrm{n}^{\circ} 28$ Campus Valonguinho, Centro - Niterói, RJ, Brasil - 24020-140 - Phone: 5521 2629-9832 - fax: 5521 2622-5739 - e-mail: emsilva@vm.uff.br

Received: February 9, 2009 - Modification: March 31, 2010 - Accepted: May 21, 2010

\section{ABSTRACT}

\begin{abstract}
O bjective: This study analyzed the degree of conversion (DC\%) of four resin-based cements (All Ceram, Enforce, Rely X ARC and Variolink II) activated by two modes (chemical and dual), and evaluated the decrease of DC\% in the dual mode promoted by the interposition of a 2.0-mm-thick IPS Empress 2 disc. Material and Methods: In the chemical activation, the resin-based cements were prepared by mixing equal amounts of base and catalyst pastes. In the dual activation, after mixing, the cements were light-activated at $650 \mathrm{~mW} / \mathrm{cm}^{2}$ for $40 \mathrm{~s}$. In a third group, the cements were lightactivated through a 2.0-mm-thick IPS Empress 2 disc. The DC\% was evaluated in a FT-IR spectrometer equipped with an attenuated total reflectance crystal (ATR). The data were analyzed by two-way ANOVA and Tukey's HSD test. Results: For all resin-based cements, the DC\% was significantly higher with dual activation, followed by dual activation through IPS Empress 2, and chemical activation $(p<0.05)$. Irrespective of the activation mode, Rely X presented the highest DC\% $(p<0.05)$. Chemically activated Variolink and All Ceram showed the worst results $(p<0.05)$. The DC\% decreased significantly when activation was performed through a 2.0-mm-thick IPS Empress 2 disc $(p<0.05)$. Conclusions: The results of the present study suggest that resin-based cements could present low DC\% when the materials are dually activated through $2.0 \mathrm{~mm}$ of reinforced ceramic materials with translucency equal to or less than that of IPS-Empress 2.
\end{abstract}

Key words: Resin cements. Cure.

\section{INTRODUCTION}

Due to their improved physicochemical properties, resin-based cements are widely used to lute metal and ceramic indirect restorations ${ }^{30}$. In general, these materials are constituted of a polymeric matrix based on dimethacrylate monomers, filler particles, pigments, and chemical substances to start their polymerization reaction ${ }^{7}$. The variation in these component contents strongly influences the physicochemical properties of the material ${ }^{2}$.

The polymerization reaction of resin-based cements can be started chemically, physically or using a dual mode that involves the two processes. In clinical practice each mode presents some advantages. For example, due to its characteristic of polymerization on-demand, physical activation allows an extension of the working time and the possibility of removing the excess cement around the restoration before the polymerization reaction has finished ${ }^{11}$. However, there will be a limitation to the use of physical activation when luting metal-ceramic or metal-free restorations produced with a high aluminum content system, e.g., Procera and In-Ceram, which prevent or decrease light transmission through the restoration ${ }^{24}$. On the other hand, chemical activation will theoretically allow the material to reach an adequate degree of conversion even in the absence of light. Thus, the dual activation mode was introduced to combine the advantages of physical and chemical activation modes. In other words, to reach an adequate degree of conversion (DC\%) irrespective of the presence of light and allow finishing immediately after luting the restoration ${ }^{3}$.

Resin-based material polymerization involves a free radical reaction in which the material is transformed from a viscous to a rigid state. During this process, the terminal aliphatic $\mathrm{C}=\mathrm{C}$ bonds are broken and converted to primary $\mathrm{C}-\mathrm{C}$ covalent bonds between methacrylate monomers. As 
polymerization progresses, however, the diffusion rate of the propagating free radicals undergoes a strong reduction. Thus, monomer conversion is not complete, and at the end of the reaction, part of the monomers remains as pendant double bonds or unreacted monomers trapped in the polymeric matrix. This amount of unconverted carbon double bonded will diminish the physical properties ${ }^{16}$, increase the degradation of the material ${ }^{8}$ and may cause damage to the pulp-dentinal complex in deep preparations ${ }^{29}$.

Although in theory dual-activated resin-based cements will develop an adequate DC\%, it is clear that clinically, the restorative materials used to produce indirect restorations will decrease the transmittance of the light emitted by the light unit, ${ }^{42}$. Moreover, the thicker the restoration, the less the light intensity to permit optimal light-activation of the resin-based cement ${ }^{13,28}$. The minimum reduction of the occlusal surfaces for posterior all-ceramic onlays and crowns is around 1.5 to $2.0 \mathrm{~mm}^{19}$. Therefore, this thickness may represent a crucial aspect for the studies carried out to investigate the behavior of resin-based cements with regard to the DC\%.

This study analyzed the DC\% of four resin-based cement started by two activation modes (chemical and dual), and evaluated the decrease of the DC\% in the dual activation mode promoted by a $2.0-\mathrm{mm}$-thick lithium disilicate-glass ceramic disc (IPS Empress 2) placed between the light-curing tip and the cement surface. The research hypothesis was that the DC\% would significantly decrease with the dual activation through the 2.0-mm-thick IPS Empress 2 disc.

\section{MATERIAL AND METHODS}

The compositions of the four resin-based cements analyzed in the present study are presented in the Figure 1. A quartz-tungsten-halogen unit (Optilux 501, Kerr, Danbury, CT, USA), using an irradiance of $650 \mathrm{~mW} / \mathrm{cm}^{2}$ for $40 \mathrm{~s}$, was used to light-activate the specimens in the dual activation mode. The radiant exposure, calculated as the product of the irradiance of the curing unit, by using a radiometer (model 100, Demetron Inc.), and the time of irradiation was 26 $\mathrm{J} / \mathrm{cm}^{2}$.

\section{Degree of Conversion ( $\mathrm{DC} \%$ )}

All the steps of DC\% measurements were carried out in a light-reduced environment. Spectra of the unpolymerized and polymerized specimens of each resin-based cement were recorded by a FTIR spectrometer ${ }^{22}$ (Varian 3100 FT-IR, Varian Inc, Palo Alto, CA, USA), equipped with an attenuated total reflectance crystal - ATR (MIRacle ATR, Pike Technologies, Madison, WI, USA) operating with 120 scans at a resolution of $4 \mathrm{~cm}^{-1}$. For unpolymerized specimens, standard amounts of base and catalyst pastes of each resin-based cement were separately compressed between two polyethylene strips and two glass slides to produce a thin film and the FT-IR spectra were obtained ${ }^{27}$. For polymerized specimens, equals amounts of base and catalyst pastes were mixed with a Teflon spatula on a mixing pad for 10 s. In Group I (chemical activation - Ch), $90 \mathrm{~s}$ after mixing, the specimens were stored in lightproof containers. In Group II (dual activation-D), immediately after mixing, the specimens were light-polymerized with the light tip in contact with a polyester strip positioned on the mixed past. In Group III (dual activation through a ceramic disc - DC), after mixing and immediately before light-polymerization, a ceramic disc $(12 \mathrm{~mm}$ in diameter and 2.0-mmthick), consisting of a 1-mm-thick framework of a castable pressed ceramic and a 1-mm-thick layering ceramic (IPS-Empress 2 system, Ivoclar Vivadent Inc, Amherst, NY, USA), was positioned between the mixed resin-based cement and the light guide tip of the light-curing unit. The framework surface was etched with $10 \%$ hydrofluoric acid for 20 s, rinsed for $30 \mathrm{~s}$, and air dried. FT-IR spectra of the polymerized specimens were recorded $24 \mathrm{~h}$ after dry storage in light-proof containers at $37^{\circ} \mathrm{C}$. Five specimens $(n=5)$ were made per group. The DC\% was calculated from the ratio between the absorbance peaks of the

\begin{tabular}{|ccccc|}
\hline Materials & Monomers & Particle size $(\mu \mathrm{m})$ & $\begin{array}{c}\text { Filler content } \\
\text { (weight \%) }\end{array}$ & Manufacturers \\
$\begin{array}{c}\text { Enforce } \\
(\mathrm{E})\end{array}$ & Bis-GMA, TEGDMA & 1 & 66 & $\begin{array}{c}\text { Dentsply, Rio de Janeiro, RJ, } \\
\text { Brazil }\end{array}$ \\
$\begin{array}{c}\text { Rely X ARC } \\
(\mathrm{R})\end{array}$ & Bis-GMA, TEGDMA & $1-5$ & 67 & $3 \mathrm{M}$ ESPE, St Paul, MN, USA \\
$\begin{array}{c}\text { Variolink II } \\
(\mathrm{V})\end{array}$ & Bis-GMA, UEDMA, TEGDMA & 0.7 & 73 & $\begin{array}{c}\text { Ivoclar Vivadent } \\
\text { Schaan, Liechtenstein }\end{array}$ \\
$\begin{array}{c}\text { All Cem } \\
(\mathrm{A})\end{array}$ & Bis-GMA, Bis-EMA, TEGDMA & $0.04-1$ & 68 & $\begin{array}{c}\text { FGM Produtos Odontológicos, } \\
\text { Joinville, SC, Brazil }\end{array}$ \\
\hline
\end{tabular}

Bis-GMA: 2,2-bis[p-(2'-hydroxy-3'methacryloxypropoxy)phenyl]propane; TEGDMA: triethylene glycol dimethacrylate; Bis-EMA: ethoxylated bisphenol A dimethacrylate UEDMA: 1,6-bis(methacryloxy-2-ethoxycarbonylamino)-2,4,4trimethylhexane

Figure 1- Resin-based luting cements used in this study 
TABLE 1- Mean values and standard deviations of the DC\%

\begin{tabular}{ccccc}
\hline \multicolumn{4}{c}{ Resin-based luting cements } & \\
Activation modes & Enforce & Rely X Arc & Variolink II & All Cem \\
\hline & & & & \\
Group I - Ch & $21.6 \pm 5.6 \mathrm{aA}$ & $38.0 \pm 6.0 \mathrm{aB}$ & $13.6 \pm 4.9 \mathrm{aC}$ & $14.2 \pm 2.9 \mathrm{aC}$ \\
Group II - DC & $35.8 \pm 3.5 \mathrm{bA}$ & $48.0 \pm 0.7 \mathrm{bB}$ & $31.2 \pm 7.5 \mathrm{bA}$ & $35.6 \pm 3.2 \mathrm{bA}$ \\
Group III - D & $59.5 \pm 4.7 \mathrm{cA}$ & $75.2 \pm 0.6 \mathrm{cB}$ & $57.4 \pm 3.6 \mathrm{cA}$ & $58.7 \pm 3.6 \mathrm{cA}$ \\
\hline
\end{tabular}

Means with same capital letter are not statistically different within the same line. Means with same lower case letter are not statistically different within the same column $(\alpha=0.05)$. Ch= chemical activation; $D C=$ ceramic dick; $D=$ dual activation.

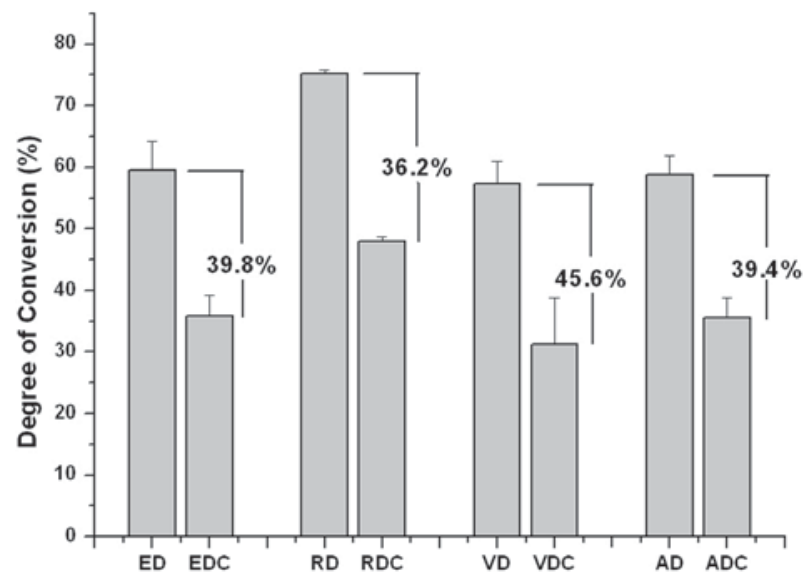

Figure 2- Decrease of DC\% for dual activation (D) through the 2.0-mm-thick IPS Empress ceramic disc. $\mathrm{E}=$ Enforce; R= Rely X ARC; V= Variolink II; A= All Cem

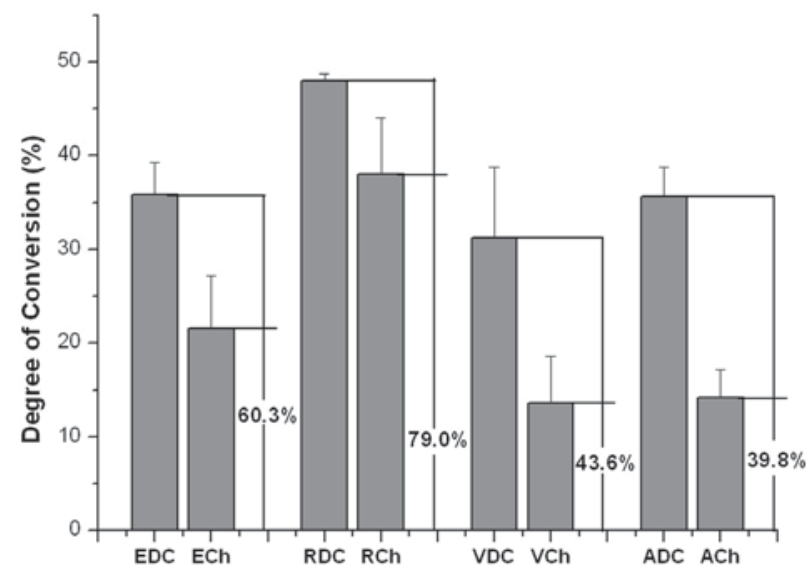

Figure 3- Comparison of the DC\% between chemical activation (Ch) and dual activation performed through 2.0 mm IPS Empress 2 ceramic disc material. $E=$ Enforce; $R=$ Rely X ARC; V= Variolink II; A= All Cem

aliphatic $\mathrm{C}=\mathrm{C}$ bond $\left(1638 \mathrm{~cm}^{-1}\right)$ to the aromatic $\mathrm{C}=\mathrm{C}$ $\left(1608 \mathrm{~cm}^{-1}\right)$, used as an internal standard, obtained from the polymerized and unpolymerized specimens by the following equation:

$$
D C(\%)=100 \times\left[1-\left(R_{\text {polymerized }} / R_{\text {unpolymerized }}\right)\right]
$$

where $\mathrm{R}=$ peak at $1638 \mathrm{~cm}^{-1} /$ peak at $1608 \mathrm{~cm}^{-1}$

\section{Statistical analysis}

Statistical analysis was performed using Statgraphics 5.1 Software (Manugistics, Rockville, $M D$, USA). After the normal distribution of the errors and the homogeneity of variance had been verified, respectively, by Shapiro-Wilk's test and Levene's test, the DC\% data were analyzed by two-way ANOVA and Tukey's HSD test for multiple comparisons. All statistical analyses were performed at a significance level of $\alpha=0.05$.

\section{RESULTS}

The results of the DC\% are presented in the Table 1. Two-way ANOVA detected a statistical significance for the two independent factors (resin-based cement and activation mode), $(p<0.05)$. Comparisons by Tukey's HSD test showed that Rely-X ARC activated by dual mode presented the highest DC\% (75.2 \pm 0.6$)$.

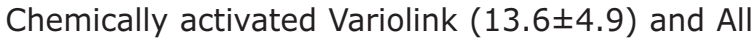

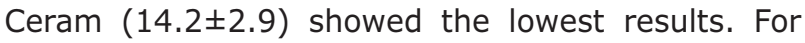
all resin-based cements, the DC\% was significantly higher with dual activation, followed by dual activation through IPS Empress 2, and chemical activation $(p<0.05)$. Irrespective of the activation mode, Rely $X$ ARC presented the highest $D C \%$ values of all the tested resin-based cements $(p<0.05)$. Figure 2 shows the decrease of DC\% for dual activation (D) through the 2.0-mm-thick IPS Empress ceramic disc (C). Comparisons of the DC\% between chemical activation (Ch) and dual activation (D) through the 2.0-mm-thick IPS Empress ceramic disc (C) is presented in Figure 3.

\section{DISCUSSION}

Among other aspects, the clinical longevity of indirect restorations is dependent upon the properties of the resin-based cement used for luting them. Moreover, the higher the DC\% of resinbased cements, the better their physicomechanical properties $^{14}$. Several studies have analyzed the polymerization of resin-based cements ${ }^{3,11-13,18,23-25}$. Most of these studies, however, have used Knoop or Vickers hardness as indicative of their degree of polymerization. Although it is well known that hardness is strongly correlated with the $\mathrm{DC} \%{ }^{7}$, it is 
reasonable to assume that inferences based on the $\mathrm{DC} \%$ of $\mathrm{C}=\mathrm{C}$ bonds could be more representative of the material behavior.

In the present study, the DC\% was evaluated after activation through a 2.0-mm-thick disc of ceramic spacer. This was made to approximate the experimental conditions to those of clinical practice. During indirect restoration luting, the ceramic will attenuate the light intensity ${ }^{4,12}$ and reduce the quantity of photons that reach the resin-based cement. The consequence is a low DC\%. IPS-Empress 2 was used in this study in view of two aspects. Firstly, according to its manufacturer (Ivoclar Vivadent Inc, Amherst, NY, USA), this material can be used to fabricate all types of posterior indirect restorations, i.e. inlays, onlays, and crowns. Secondly, published studies ${ }^{9,10}$ have shown that IPS-Empress 2 has a translucency equal to or greater than that of other reinforcedceramic materials indicated for building up posterior indirect restorations, i.e., Procera, In Ceram Alumina and In Ceram Zirconia. Thus, the rationale was that the results obtained here could be extrapolated to the other ceramic materials with translucency equal to or less than that of IPS Empress 2.

According to Ivoclar Vivadent (IPS-Empress 2's manufacturer) the framework surface of this ceramic system must be etched with $10 \%$ hydrofluoric acid for $20 \mathrm{~s}$ before luting it. Thus, reinforcing the attempt to approximate the experimental protocol as closely as possible to clinical practice, the IPS-Empress 2 surface was etched with $10 \%$ hydrofluoric acid for 20 $\mathrm{s}$ before resin-based cements were light-polymerized.

For all the cements analyzed in this study, the DC\% in the dual activation mode was significantly reduced when the materials were light-activated through IPS Empress 2 (Table 1). Thus, the research hypothesis was proved. This result was expected and can be explained by the light attenuation promoted by IPS Empress $2^{4}$. During light-activation, the light that passes through the ceramic is absorbed and scattered. Thus, the light irradiance produced by the light source is attenuated and its effectiveness is reduced as the ceramic thickness increases. Therefore, Meng, et al. ${ }^{21}$ (2006) showed that a light intensity of $800 \mathrm{~mW} / \mathrm{cm}^{2}$ was reduced to $160 \mathrm{~mW} /$ $\mathrm{cm}^{2}$ after being transmitted through $2.0 \mathrm{~mm}$ of a machinable ceramic. Furthermore, El-Mowafy, et al. ${ }^{5}$ (1999) analyzing the hardening of 8 resin-based cements dual-polymerized through 1-6-mm-thick ceramic spacer, showed that hardness decreased significantly when ceramic thickness was 2-3 mm or more. In the same study, the curing-light intensity fell by about $75 \%$ through a 1 -mm-thick ceramic spacer. Since clinicians believe that even in absence of light, dual-resin-based cements will develop a suitable DC\%, these findings assume crucial importance. If resin-based cements reach a low DC\%, their physicomechanical properties will certainly decrease. Consequently, the clinical performance of indirect restorations could be compromised.

On the other hand, the results obtained in the present study disagree with those of Caughman, et al. $^{3}$ (2001), who showed a DC\% of up to $50 \%$ for 6 resin cements, including Variolink II, when polymerized through a 3-mm-thick disc of a dental porcelain (Ceramco, Ceramco Inc, Burlington, NJ, USA). However, there are two important aspects to discuss here. Firstly, Ceramco is a feldspathic porcelain that presents a higher translucency than IPS-Empress $2^{1}$. This difference in optical behavior certainly justifies the discrepancy between the results of the two studies. Secondly, because of its superior mechanical properties, IPS-Empress 2 is more suitable for building up posterior indirect restorations ${ }^{6}$. From this viewpoint, it is reasonable to claim the results of the present study as representative of the behavior of resin-based cements when light-activated through ceramic materials suitable for producing indirect restorations.

Several studies have claimed that when resinbased cements are polymerized in a dual mode, the chemical component of polymerization can be hindered by the faster reaction promoted by the lightactivation ${ }^{17}$. This behavior could be explained by the polymerization kinetics of dimethacrylate matrixes. When light-activation begins, several growth centers are formed and the matrix is transformed from a liquid to a viscous state by producing a large polymer network, i.e. a gelation process. After gelation, the polymeric network becomes highly crosslinked and the propagation and termination steps of polymerization, which involve the link between monomers and oligomers with the polymer network, are restricted, i.e., diffusion is limited ${ }^{26}$.

Taking into account that the chemical reaction occurs at a slower rate than the physical one, it is probable that the free radicals formed by the chemical component of polymerization are entrapped in the polymer network, so they could not contribute to an increase in the overall $\mathrm{DC} \%{ }^{15,23}$. This was corroborated by the findings of Meng, et al. ${ }^{20}$ (2008), who showed that even under low light intensity irradiation, dual-polymerized luting cements still had a large amount of free radicals, mostly from chemical catalysts trapped in the hardening resin matrix, which did not contribute to the overall DC\% of materials. For Variolink and All Cem, the DC\% after chemical activation reached only $43.6 \%$ and $39.8 \%$, respectively, compared with the DC\% after dual activation through IPS Empress 2 (Figure 2). Considering the above discussion and the findings of Meng, et al. ${ }^{20}$ (2008), it is reasonable to speculate that the chemical component of polymerization of these cements contributed very little to the total DC\% after dual activation through IPS Empress 2.

From Table 1, it can be noted that chemically activated Variolink II presented the lowest DC\%. This result is in agreement with those of previous studies $^{1,12,16}$. According to El-Mowafy, et al. ${ }^{5}$ (1999) the variability in hardness presented by chemically activated resin-based cements is most likely due to the way these cements are formulated. In other 
words, the higher the amount of chemical catalyst in their formulation, the greater the hardness of the materials. In the above-mentioned study, the hardness of chemically activated Enforce increased $23.57 \%$ (from 32.1 to 42 ) after $24 \mathrm{~h}$, while with Variolink II, this increase was only $17.2 \%$ (from 7.7 to 9.3). Furthermore, in a recent study, Ozyesil, et al. ${ }^{23}$ (2004) found no difference in the DC\% of Variolink II when light-polymerized and dual-polymerized through a 2.0-mm-thick disc of Empress 2. Based on these studies, it is reasonable to hypothesize that Variolink II has lower chemical catalyst content than Enforce and Rely X ARC. The statistical similarity between the results of Variolink II and All Cem in the chemically activated group (Table 1 ) allows one to assume that these resin-based cements have a similar content of chemical initiators.

Rely $X$ ARC presented the highest DC\% under the three polymerization conditions (Table 1 ). It also can be noted that its DC\% when dual polymerized

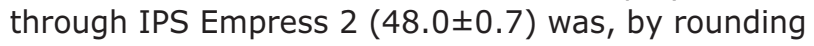
off, close to $50 \%$. Moreover, the DC\% after chemical activation reached $79 \%$ compared with the DC\% after dual activation through IPS Empress 2. These results allow one to suppose that this resin-based cement presents a larger amount of chemical and physical initiators than the other three resin-based cements analyzed in the present study.

\section{CONCLUSIONS}

The results of the present study suggest that resin-based cements could present low degree of conversions when the materials are dually activated through $2.0 \mathrm{~mm}$ of reinforced ceramic materials with translucency equal to or less than that of IPSEmpress 2.

\section{ACKNOWLEDGEMENTS}

The authors are grateful to FGM Produtos Odontológicos and to 3M ESPE for supplying the materials used in this study, and to the Institute of Macromolecules of the Federal University of Rio de Janeiro (IMA/UFRJ) for performing the DC\% measurements.

\section{REFERENCES}

1- Antonson SA, Anusavice KJ. Contrast ratio of veneering and core ceramics as a function of thickness. Int J Prosthodont. 2001;14:31620.

2- Braga RR, Cesar PF, Gonzaga CC. Mechanical properties of resin cements with different activation modes. J Oral Rehabil. 2002;29:257-62.

3- Caughman WF, Chan DCN, Rueggeberg FA. Curing potential of dual-polymerizable resin cements in simulated clinical situations. J Prosthet Dent. 2001;86:101-6.

4- Dias MC, Piva E, Moraes RR, Ambrosano GMB, Sinhoreti MAC, Correr-Sobrinho L. UV-Vis spectrophotometric analysis and light irradiance through hot-pressed and hot-pressed-veneered glass ceramics. Braz Dent J. 2008;19:197-203.

5- El-Mowafy OM, Rubo MH, El-Badrawy WA. Hardening of new resin cements cured through a ceramic inlay. Oper Dent. 1999;24:38-44.
6- Esquivel-Upshaw JS, Anusavice KJ, Yang MC, Lee RB. Fracture resistance of all-ceramic and metal-ceramic inlays. Int J Prosthodont. $2001 ; 14: 109-14$.

7- Ferracane JL, Greener EH. The effect of resin formulation on the degree of conversion and mechanical properties of dental restorative resins. J Biomed Mater Res. 1986;20:121-31.

8- Gonçalves L, Noronha Filho JD, Guimarães JGA, Poskus LT, Silva EM. Solubility, salivary sorption and degree of conversion of dimethacrylate-based polymeric matrixes. J Biomed Mater Res B Appl Biomater. 2008;85:320-5.

9- Heffernan MJ, Aquilino SA, Diaz-Arnold AM, Haselton DR, Stanford CM, Vargas MA. Relative translucency of six all-ceramic systems. Part I: core materials. J Prosthet Dent. 2002;88:4-9.

10- Heffernan MJ, Aquilino SA, Diaz-Arnold AM, Haselton DR, Stanford CM, Vargas MA. Relative translucency of six all-ceramic systems. Part II: core and veneer materials. J Prosthet Dent. 2002;88:10-5.

11- Hofmann N, Papsthart G, Hugo B, Klaiber B. Comparison of photo-activation versus chemical or dual-curing of resin-based luting cements regarding flexural strength, modulus and surface hardness. J Oral Rehabil. 2001;28:1022-8.

12- Ilie N, Hickel R. Correlation between ceramics translucency and polymerization efficiency through ceramics. Dent Mater. 2008;24:908-14.

13- Jung H, Friedl KH, Hiller KA, Furch H, Bernhart S, Schmalz G. Polymerization efficiency of different photocuring units through ceramic discs. Oper Dent. 2006;31:68-77.

14- Jung $H$, Friedl KH, Hiller KA, Haller A, Schmalz G. Curing efficiency of different polymerization methods through ceramic restorations. Clin Oral Investig. 2001;5:156-61.

15- Komori PCP, Paula AB, Martin AA, Tango RN, Sinhoreti MAC, Correr-Sobrinho L. Effect of light energy density on conversion degree and hardness of dual-cured resin cement. Oper Dent. 2010;35:120-4.

16- Kunbuloglu O, Lassila LV, User A, Vallitu PK. A study of the physical and chemical properties of four resin composite luting cements. Int J Prosthodont. 2004;17:357-63.

17- Lee IB, Um CM. Thermal analysis on the cure speed of dual cured resin cements under porcelain inlays. J Oral Rehabil. 2001;28:18697.

18- Lopes LG, Franco EB, Neto NA, Herrera FS, Kurachi C, Castañeda-Espinosa JC, et al. Polymerization of a dual-cured cement through ceramic: led curing light vs. halogen lamp. J Appl Oral Sci. 2004; 12:312-6.

19- Marchack BW, Futatsuki Y, Marchack CB, White SN. Customization of milled zirconia copings for all-ceramic crowns: a clinical report. J Prosthet Dent. 2008;99:169-73.

20- Meng $X$, Yoshida $K$, Atsuta $M$. Influence of ceramic thickness on mechanical properties and polymer structure of dual-cured resin luting agents. Dent Mater. 2008;24:594-9.

21- Meng X, Yoshida K, Atsuta M. Hardness development of dualcured resin cements through different thicknesses of ceramics. Dent Mater J. 2006;25:132-7.

22- Moraes LGP, Rocha RSF, Menegazzo LM, Araújo EB Yukimitu $\mathrm{K}$, Moraes JCS. Infrared spectroscopy: a tool for determination of the degree of conversion in dental composites. J Appl Oral Sci. 2008;16:145-9.

23- Ozyesil AG, Usumez A, Gunduz B. The efficiency of different light sources to polymerize composite beneath a simulated ceramic restoration. J Prosthet Dent. 2004;91:151-7.

24- Rasetto FH, Driscoll CF, Prestipino V, Masri R, Von Fraunhofer JA. Light transmission through all-ceramic dental materials: a pilot study. J Prosthet Dent. 2004;91:441-6.

25- Reges RV, Costa AR, Correr AB, Piva E, Puppin-Rontani RM, Sinhoreti MAC, et al. Effect of light-curing units, post-cured time and shade of resin cement on Knoop hardness. Braz Dent J. 2009;20:410-3.

26- Sideridou I, Tserki V, Papanastasiou G. Effect of chemical structure on degree of conversion in light-cured dimethacrylatebased dental resins. Biomaterials. 2002;23:1819-29.

27- Sostena MMDS, Nogueira RA, Grandini CR, Moraes JCS. Glass transition and degree of conversion of a light-cured orthodontic composite. J Appl Oral Sci. 2009;17:570-3.

28- Tezvergil-Mutluay A, Lassila LV, Vallittu PK. Degree of conversion of dual-cure luting resins light-polymerized through various materials. Acta Odontol Scand. 2007;65:201-5.

29- Thonemann B, Schmalz G, Hiller KA, Schweikl H. Responses of L929 mouse fibroblasts, primary and immortalized bovine dental papilla-derived cell lines to dental resin components. Dent Mater. 2002;18:318-23.

30- White SN, Yu Z. Physical properties of fixed prosthodontic, resin composite luting agents. Int J Prosthodont. 1993;6:384-9. 